\title{
Localization of kisspeptin neurons in the hypothalamus of peripubertal female lambs; possible connection with gonadotrophin releasing hormone and neuropeptide $Y$ neurons
}

\author{
J. Polkowska' ${ }^{1,3}$, S. Picard ${ }^{2}$, M. Wańkowska ${ }^{1}$, M.Cieślak ${ }^{1}$, A. Caraty ${ }^{2}$ and Y. Tillet ${ }^{2}$ \\ ${ }^{1}$ The Kielanowski Institute of Animal Physiology and Nutrition, Polish Academy of Sciences, 05-110 Jabłonna, Poland \\ 2 Université François Rabelais de Tours, Unité Physiologie de la Reproduction et des Comportements, INRA Centre Val de Loire \\ CNRS, UMR7247, FED4226 Neuroimagerie Fonctionnelle, 37380 Nouzilly, France
}

KEY WORDS: kisspeptin, neuropeptide $Y$, gonadotrophin releasing hormone, hypothalamus, puberty, sheep

Received: 25 September 2013

Revised: 28 April 2014

Accepted: 12 June 2014

${ }^{3}$ Corresponding author:

e-mail: j.polkowska@ifzz.pan.pl

\begin{abstract}
Hypothalamic peptide kisspeptin $(\mathrm{kp})$ plays a major role in the initiation of pubertal events in mammals through the activation of gonadotrophin-releasing hormone $(\mathrm{GnRH})$ neurons. The present study was designed to analyse the morpho-functional role of kisspeptin cells in the multimodal effects on $\mathrm{GnRH}$ secretion in female prepubertal lambs. The localization of $\mathrm{kp}$ immunoreactive (ir) expression was compared with that of $\mathrm{GnRH}$ release and neuropeptide Y (NPY) synthesis. The experiment was conducted on eight 32-week-old Merino lambs. The distribution of the peptides was estimated using immunohistochemistry and anti-kp, anti-GnRH and anti-NPY specific antibodies. The hypothalamic area containing numerous $\mathrm{kp}$-ir perikarya and a dense network of $\mathrm{kp}$-ir fibres was localized in the caudal part of the arcuate nucleus. Single axons and single perikarya were observed throughout the hypothalamus extending from the preoptic area to the mammillary bodies. Distinct bundles of kp-ir nerve terminals were observed in the lateral zone of the median eminence (ME) and dispersed in smaller quantities in its medial zone. Double immunostaining indicated that a third of the kp-ir neurons were in close apposition with NPY-ir afferents, and that the distribution of $\mathrm{kp}$-ir nerve terminals in the ME matched that of $\mathrm{GnRH}$-ir nerve terminals. To conclude, the presence of very large numbers of kp-ir neurons in the peripubertal period could be attributed to their stimulating action on the $\mathrm{GnRH}$ neuronal system during this period. This influence could act directly in the ME, where both peptides are released. In addition, kp-ir neurons could mediate the effect of NPY on GnRH secretion.
\end{abstract}

\section{Introduction}

The kisspeptin (kp) family of peptides comprises products of the Kiss 1 gene that essentially take part in the neuroendocrine regulation of reproductive processes in mammals. All kisspeptins share a 10-amino-acid C-terminal region and activate the receptor GPR54 to the same degree (Kotani et al., 2001). Experimental evidence indicates that in sheep, similarly as in rodents, $\mathrm{kp}$ is involved in many reproductive processes, including the negative and positive feedback of sex steroids in 
gonadotrophin secretion (Estrada et al., 2006; Smith et al., 2006a), generation of the preovulatory surge of gonadotrophin-releasing hormone $(\mathrm{GnRH}$; (Smith et al., 2006b; Caraty et al., 2007), and photoperiodic control of reproduction in seasonal breeders (Smith et al., 2009a; Chalivoix et al., 2010). Kisspeptin-GPR54 also plays a key role in the timing of the onset of puberty (De Roux et al., 2003; Seminara et al., 2003; Clarkson et al., 2010). The character of $\mathrm{kp}$ in mediating puberty in the sheep is still, however, less understood, in contrast with rodents and monkeys (reviewed by Przekop and Ciechanowska, 2012).

Kisspeptin neurons have been located by immunohistochemistry in luteal phase ewes after treatment with colchicine (Franceschini et al., 2006) and in ovariectomized ewes (Smith et al., 2011), as well as in intact rams (Cheng et al., 2010). There is general agreement that, the $\mathrm{kp}$ neuronal system in this species is organized so that the main centre of $\mathrm{kp}$ synthesis is located in the arcuate (ARC) nucleus and some minor clusters of $\mathrm{kp}$-cell bodies occur in the medial preoptic area (MPOA) (Franceschini et al., 2006; Smith et al., 2011). A similar pattern has been described in the equine hypothalamus (Decourt et al., 2008). The results obtained in ruminants and horses differ from those in rodents, where the main centre of kp perikarya responsible for the positive feedback action of gonadal steroids is located in the anteroventral periventricular nucleus (AVPV) (De la Iglesia and Schwartz, 2006).

Some direct morphological connections between $\mathrm{kp}$ and GnRH neurons in the MPOA, have been observed in mice (Clarkson and Herbison, 2006). Other studies have shown that this contact takes place at the level of the median eminence (ME). Arcuate kp neurons have also been shown to project to this organ (Smith et al., 2011). Close apposition of $\mathrm{GnRH}$ and $\mathrm{kp}$ fibres has been observed in the ME of the mare (Decourt et al., 2008) and the goat (Ohkamura et al., 2009). Thus, to date, neural transmission from $\mathrm{kp}$ to GnRH neurons is not completely understood in sheep and need further study.

In addition to $\mathrm{kp}$-ir neurons, neuropeptide $\mathrm{Y}$ (NPY) participates in the control of GnRH neuronal activity. This peptide is largely distributed in the central nervous system (CNS) and its role in reproductive functions is attributed to the population of neurons located in the ARC nucleus (Kalra and Crowley, 1992). In sheep, NPY can stimulate GnRH/LH release during high ovarian activity (Wójcik-Gładysz et al., 2003) and plays an important role in the preovulatory surge (Porter et al., 1993; Polkowska et al., 2006). Moreover, synaptic contacts between NPY-containing fibres and GnRHperikarya have been documented in sheep (Norgren et al., 1989; Tillet et al., 1989).

This study had three main aims: the first was to locate the $\mathrm{kp}$ neuronal system in the hypothalamus of intact female lambs in the period just before puberty; the second was to establish the possible morphological connections between NPY fibres and $\mathrm{kp}$ neurones, two major regulators of puberty; the third was to identify the putative site of interaction between $\mathrm{kp}$ and GnRH. To this end, single and double immunohistochemical staining was used.

\section{Material and methods}

\section{Animals}

The study was performed on purebred Polish Merino female lambs born during the first 10 days of February. The animals were maintained indoors under natural lighting conditions $\left(52^{\circ} \mathrm{N}, 21^{\circ} \mathrm{E}\right)$ in individual pens and had visual contact with their neighbours throughout the study. They were fed a diet of commercial concentrates with hay and water available at libitum. At the beginning of the sixth month of age, peripheral blood samples were taken weekly by venipuncture to monitor progesterone levels in blood plasma. Blood sampling was then conducted every two days in sheep 28-38 weeks of age. Eight lambs exhibiting low concentrations of progesterone and weighing $32 \pm 2.8 \mathrm{~kg}$ were chosen for the experimental peripubertal group. They were slaughtered at 32 weeks of age by decapitation under pentobarbital anaesthesia in the local abattoir. Four sheep were kept alive to determine the precise timing of puberty using a mature vasectomized Merino ram. Under normal environmental and nutritional conditions, the onset of puberty in Polish Merino lambs occurs at the age of 33 weeks. The ovaries of experimental lambs were examined post-mortem.

The experimental procedures were approved by the Local Ethics Committee of the Warsaw Agricultural University according to the Polish Guidelines for the Care and Use of Animals (August 2, 1997)

\section{Immunohistochemistry}

Single staining. Immediately after decapitation, the brain from each sheep was perfused both carotid arteries with $1500 \mathrm{ml} 0.1 \mathrm{M}$ phosphate buffered saline (PBS) and subsequently with $2000 \mathrm{ml}$ 0.1 M PBS containing 4\% paraformaldehyde $(\mathrm{w} / \mathrm{v})$ $\mathrm{pH}$ 7.4. The hypothalami were dissected out $20 \mathrm{~min}$ after the beginning of perfusion and post-fixed for a further $72 \mathrm{~h}$ by immersion in the same fixative. 
They were cut into blocks of the same dimension and from the same area. The tissue was then washed with $0.1 \mathrm{M}$ PBS, cryoprotected in a $20 \%$ sucrose solution in $0.1 \mathrm{M}$ PBS for at least 2 days, and stored at $-70^{\circ} \mathrm{C}$. The hypothalamic blocks were thawed to $10^{\circ} \mathrm{C}$ and cut on a cryostat (Jung CM 1500, Leica Instruments $\mathrm{GmbH}$, Nussloch, Germany) in the coronal plane in $30 \mathrm{~mm}$ thick sections, between the septum and mammillary bodies, including the MPOA, the organum vasculosum of the lamina terminalis (OVLT), the anterior hypothalamic area (AHA), the medial basal hypothalamus (MBH), the ME and the pituitary stalk (PS). Hypothalamic nuclei were identified using the atlas of the sheep brain developed by Welento et al. (1969). Sections were then washed in a washing solution containing $0.3 \%$ Triton $\mathrm{X}-100$ and $0.05 \% \mathrm{NaN}_{5}$ in $0.1 \mathrm{M}$ PBS and subsequently incubated for $4 \mathrm{~h}$ in $1 \%$ hydrogen peroxide in washing solution and for $24 \mathrm{~h}$ in 3\% preimmune lamb serum in washing solution. The sections were incubated for seven days at $4{ }^{\circ} \mathrm{C}$ with the following primary antisera: anti kp-10 (Francheschini et al., 2006) diluted 1:20,000 and 1:40,000, anti-NPY (cat. no. 9528; Sigma, St. Louis, USA) diluted 1:4,000, or antihLHRH (cat. No. 11175, MP Biomedical LLC, Ohio, USA) diluted 1:800. Antisera were diluted in washing solution containing $0.1 \%$ human serum albumin. After incubation with the primary antibody, the sections were rinsed in $0.01 \mathrm{M}$ PBS and incubated for $24 \mathrm{~h}$ at room temperature with the secondary antibody (sheep antirabbit Ig $[\mathrm{H}+\mathrm{L}]$ labelled with peroxidase (Bio-Rad, France)), diluted $1: 400$ with $0.1 \%$ normal lamb serum in washing solution. The colour reaction was developed by incubating sections with $0.05 \%$ 3'3-diaminobenzidine tetrachloride chromogen (Sigma) and $0.001 \%$ hydrogen peroxide in $0.05 \mathrm{M}$ TRIS buffer. The material was then stained using the silver intensification method according to Liposits et al. (1984).

In control sections, primary antisera were replaced with the same dilution of non-immune rabbit serum. To evaluate the specificity of staining, the anti-hormone serum was inhibited with its homologous antigen. Before incubation, $\mathrm{kp}$ antiserum was pre-incubated with $20 \mathrm{ng} \cdot \mathrm{ml}^{-1}$ synthetic mouse $\mathrm{kp}$ (NeoMPS, Strasbourg, France), NPY antiserum, with $10 \mu \mathrm{g} \cdot \mathrm{ml}^{-1} \mathrm{NPY}$ (cat. no 6269, Sigma), and LHRH antiserum, with $10 \mu \mathrm{g} \cdot \mathrm{ml}^{-1}$ synthetic GnRH (UCB, Belgium) to block the immunostaining. Antigens and antisera were mixed and preincubated for $24 \mathrm{~h}$ at $+4^{\circ} \mathrm{C}$ before being used. None of the control staining showed any specific staining (data not shown).

\section{Double staining}

Double immunostaining for $\mathrm{kp}$ and NPY was used in three animals. Sections from the caudal as- pect of the arcuate nucleus (ARC) were simultaneously incubated with a mixture of anti-kp raised in rabbit and diluted 1:2,000 and with anti-NPY raised in guinea pig and diluted 1: 5,000 according to a previously described procedure (Chaillou et al., 1998; Tillet et al., 2010). After three washes, the primary antibodies were detected using immunofluorescence by incubating the sections simultaneously in a mixture of fluorescent donkey immunoglobulin antiguinea pig IgG (CyTM)I diluted 1:1,000 and antirabbit IgG (fluoroprobe 488) diluted 1:500 (Jackson Immunoresearch Laboratories Inc.). Primary and secondary antisera were diluted in PBS containing $0.3 \%$ TritonX100, $0.1 \%$ sodium azide, and $0.1 \%$ human serum albumin.

The specificity of the anti-kp and anti-NPY antisera has been demonstrated previously (Franceschini et al., 2006; Ciofi et al., 2009). The specificity of the double immunostaining was checked by incubating each primary antiserum with both secondary fluorescent-labelled immunoglobulins.

\section{Image analyses}

Single staining. A Nikon type 104 projection microscope (Nikon Corporation, Yokohama, Japan) was used to analyse hypothalamic sections. Staining was analysed using image analysis software ('Lucia' version 3.51ab, Laboratory Imaging Ltd., Prague, Czech Republic). Immunostained sections were projected by camera (Panasonic KR222, Matsushita Electric Industrial Co., Osaka, Japan) on to a colour monitor. Images were adjusted for optimal contrast, fixed at the same brightness levels and saved in a buffering system. Qualitative analyses of neuron distribution and morphology were conducted in every fifth section through the MPOA including the OVLT, every tenth section through the AHA on both sides of the third ventricle of the brain $(3 \mathrm{v})$, and every fifth section of the MBH-containing structure of the ME extending from its rostral to caudal aspect. Analyses were performed under a $40 \times$ objective lens for perikarya, fibre varicosities, and nerve terminal distribution.

Double staining. The double immunofluorescent staining was observed under a confocal microscope, Zeiss LSM 700 (Carl Zeiss, O Berkochen, Germany), fitted with four laser diodes (excitation wavelength $405 \mathrm{~nm}, 488 \mathrm{~nm}, 555 \mathrm{~nm}$ and $639 \mathrm{~nm}$ ). Image analysis was performed under a $40 \times$ oil immersion objective (Plan-Apochromat, $40 \times / 1.3$ oil DIC M27), using ZEN control software. The thickness of the optical sections was $0.3 \mu \mathrm{m}$. Homogenously distributed kp-immunoreactive neurons in the ARC nucleus (17-45 per animal) were 
analysed in each lamb, and a fibre and a neuron were considered to be in contact or in close apposition when contact was observed on two successive focal plans and when the distance between the maximum staining intensity was less than $0.2 \mu \mathrm{m}$.

\section{Progesterone assays in peripheral blood plasma}

Plasma progesterone was assayed in duplicate $100 \mu \mathrm{g}$ aliquots using a direct RIA method routinely used in our laboratory following the procedure described by Stupnicki and Kula (1982) with a sensitivity of $6.2 \mathrm{pg} \cdot \mathrm{ml}^{-1}$. The intra-assay coefficient of variation was $<10 \%$.

\section{Results}

\section{Reproductive status of animals}

None of the experimental lambs had reached puberty. The progesterone concentration in blood plasma did not exceed $0.5 \mathrm{ng} \cdot \mathrm{ml}^{-1}$. Inspection of their ovaries revealed no corpora lutea and at least one dominant ovarian follicle of about $6-7 \mathrm{~mm}$ in diameter. Monitoring the plasma progesterone concentration and oestrous behaviour in the four living sheep revealed that the first successful behavioural oestrous checked by ram occurred at $33 \pm 05$ (mean $\pm \mathrm{SD}$ ) weeks of age. At this time the plasma progesterone concentrations rose to $1 \mathrm{ng} \cdot \mathrm{ml}^{-1}$.

\section{The distribution and morphology of kp neurons}

Kisspeptin immunoreactivity (kp-ir) was detectable in the cytoplasm of both cell bodies and fibres. Single kp-ir axons were observed in the MPOA area including the OVLT and throughout all of the hypothalamus from the recessus supraopticus up to the mammillary bodies. They ran parallel to the wall of the third ventricle and usually close to the wall. Perikarya positive for $\mathrm{kp}$ immunolabeling were localized in three areas: the MPOA area above the OVLT (Figure 1), the AHA (Figure 1) and the ARC nucleus (Figure 2). In the first two areas, the cell bodies were rare and very weakly stained (Figure 1). The ARC nucleus contained a large number of strongly stained $\mathrm{kp}$-ir perikarya and fibres, with more kp-ir neurons per section in the medial and caudal parts of the ARC nucleus than its rostral part (Figure 2). They were particularly abundant in the area adjacent to the recessus mammilaris. The average number of labelled $\mathrm{kp}$ perikarya in these areas was $155 \pm 16(n=8$; mean $\pm S D)$ cells per section. Perikarya from the three distinct areas showed the same round shape. They were mostly classified as uni- or bipolar according to the number of neuronal processes. The diameter of the cell bodies did not exceed 10-15 $\mu \mathrm{m}$. The average surface of $\mathrm{kp}$-ir cells from the MPOA and AHA did not differ from that of kp-ir perikarya from the ARC $(91.7 \pm 6.1$ vs $90.4 \pm 5.7 \mu \mathrm{m}^{2}$; mean $\pm \mathrm{SD}$ ).

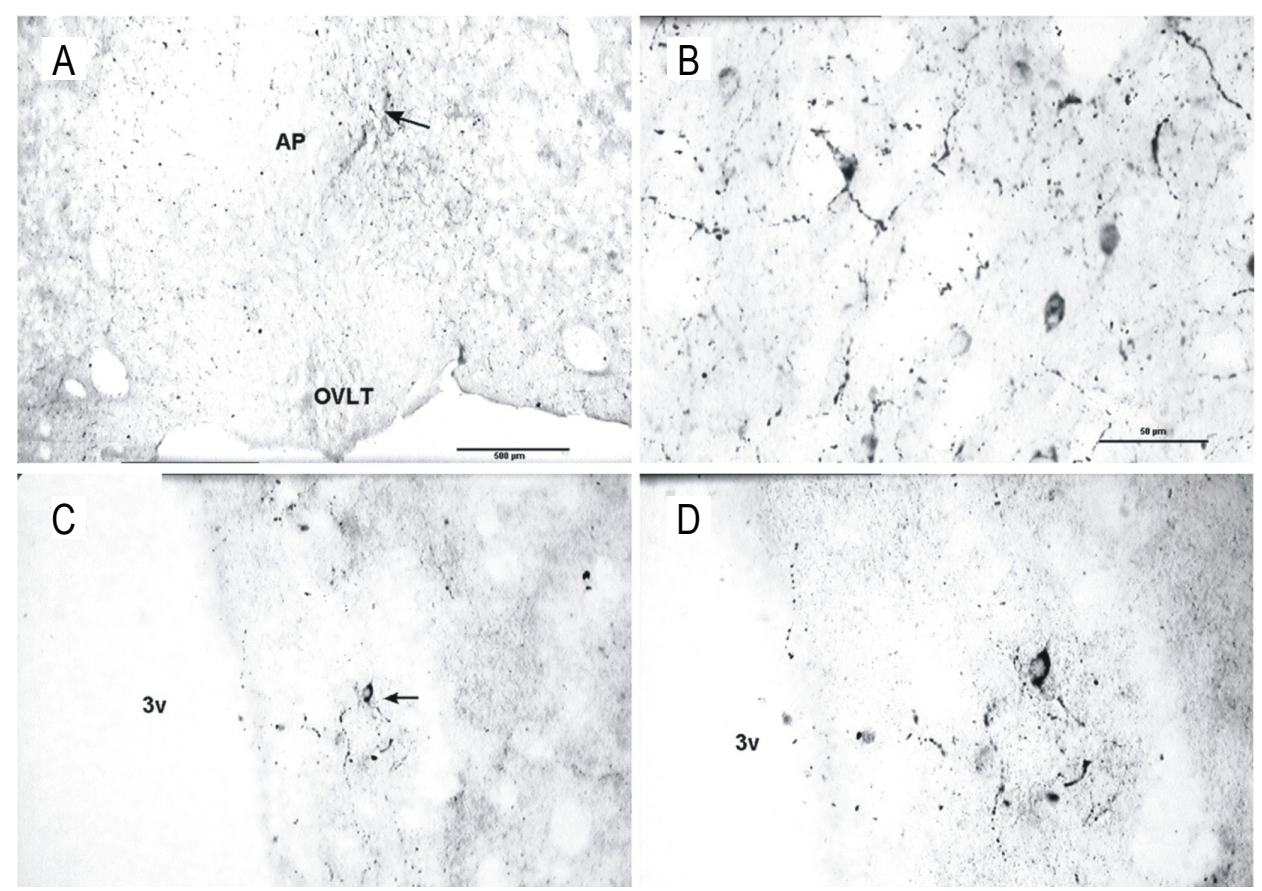

Figure 1. The population of immunoreactive kisspeptin perikarya and fibres in the preoptic area $(A, B)$ and periventricular nucleus (C, D) of a representative peripubertal lamb. The right panel represents a higher magnification of the left panel. $3 \mathrm{v}$ - third ventricle; AP - preoptic area; OVLT - organum vasculosum of the lamina terminalis; scale bars: $A, C=200 \mu \mathrm{m} ; B, D=50 \mu \mathrm{m}$ 


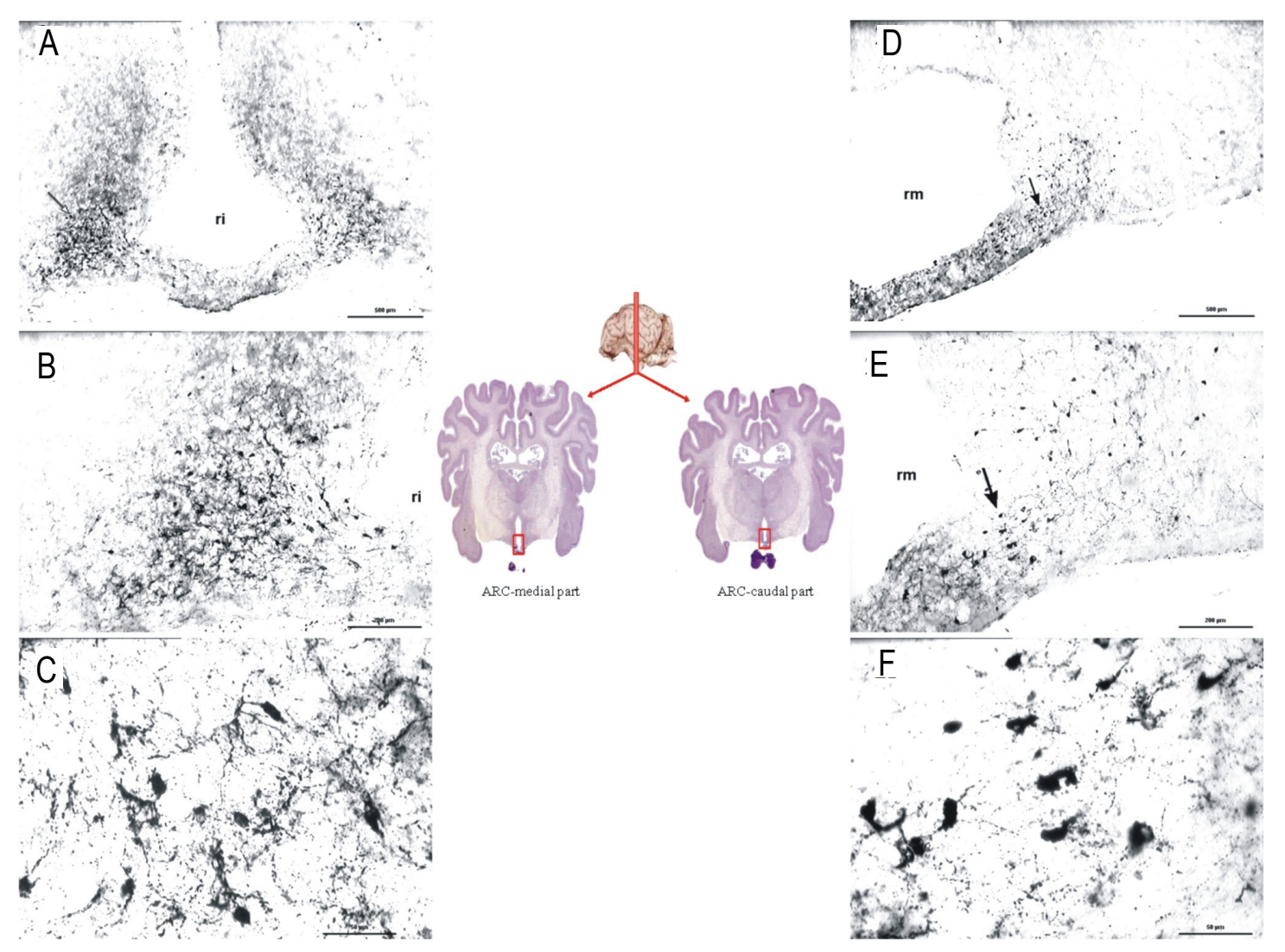

Figure 2. The population of immunoreactive kisspeptin perikarya and fibres in the medial $(A, B, C)$ and caudal parts $(D, E, F$ of the arcuate nucleus of a representative peripubertal lamb. In the middle: histological frontal planes of the sheep brain, the medial (left) and caudal (right) parts of the arcuate nucleus are marked. ri- recessus infundibularis, rm- recessus mammilaris; scale bars: $A, D=500 \mu \mathrm{m} ; B, E=200 \mu \mathrm{m} ; C, F=.50 \mu \mathrm{m}$

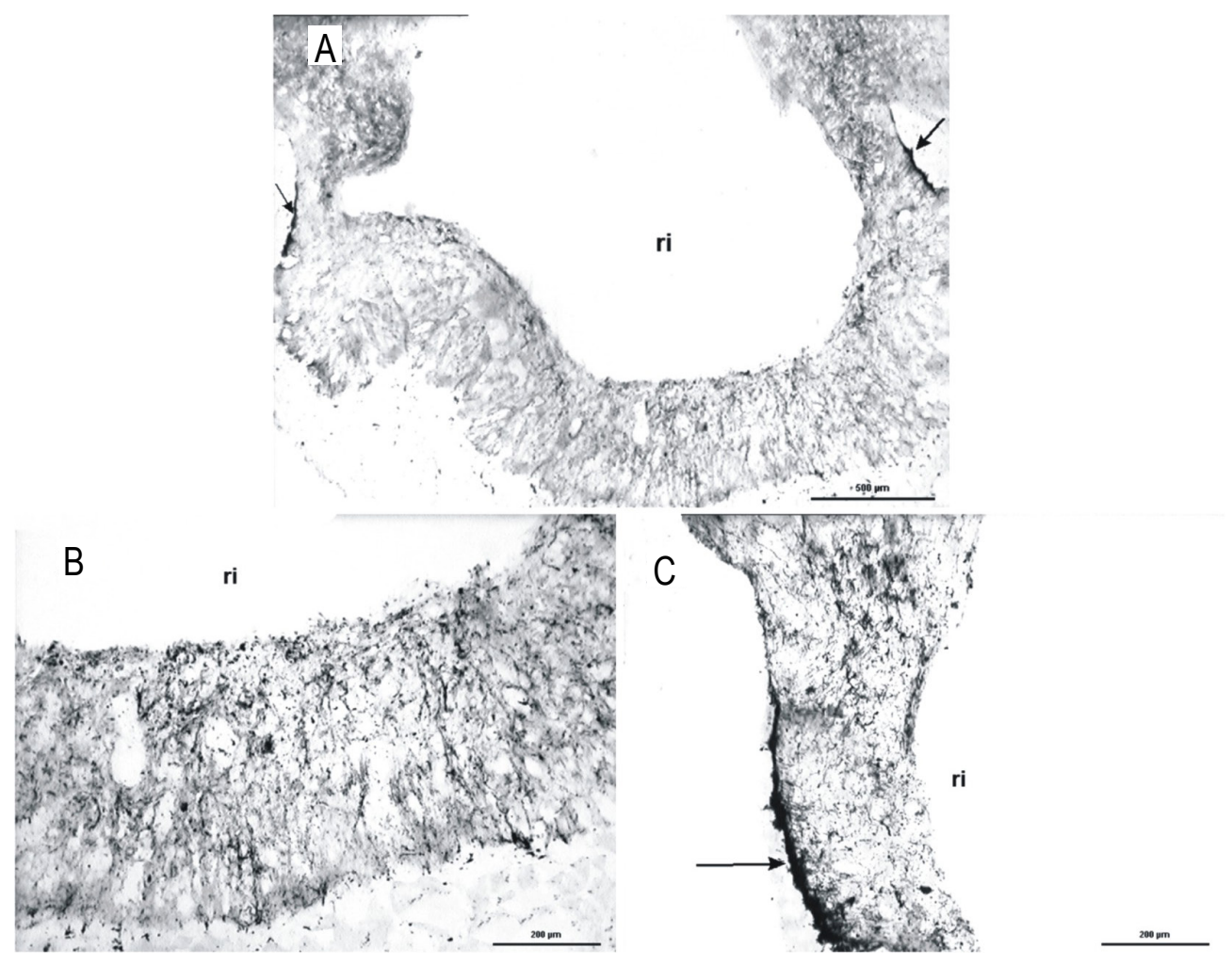

Figure 3. Immunoreactive kisspeptin nerve terminals in the medial part of the median eminence of a representative peripubertal lamb (A). Dispersed distribution of kp-ir nerve terminals in the medial zone $(B)$ and bundles of kp-ir nerve terminals in the lateral zone $(C)$ of the median eminence ri- recessus infundibularis; scale bars: $A=500 \mu \mathrm{m} ; \mathrm{B}, \mathrm{C}=200 \mu \mathrm{m}$ 

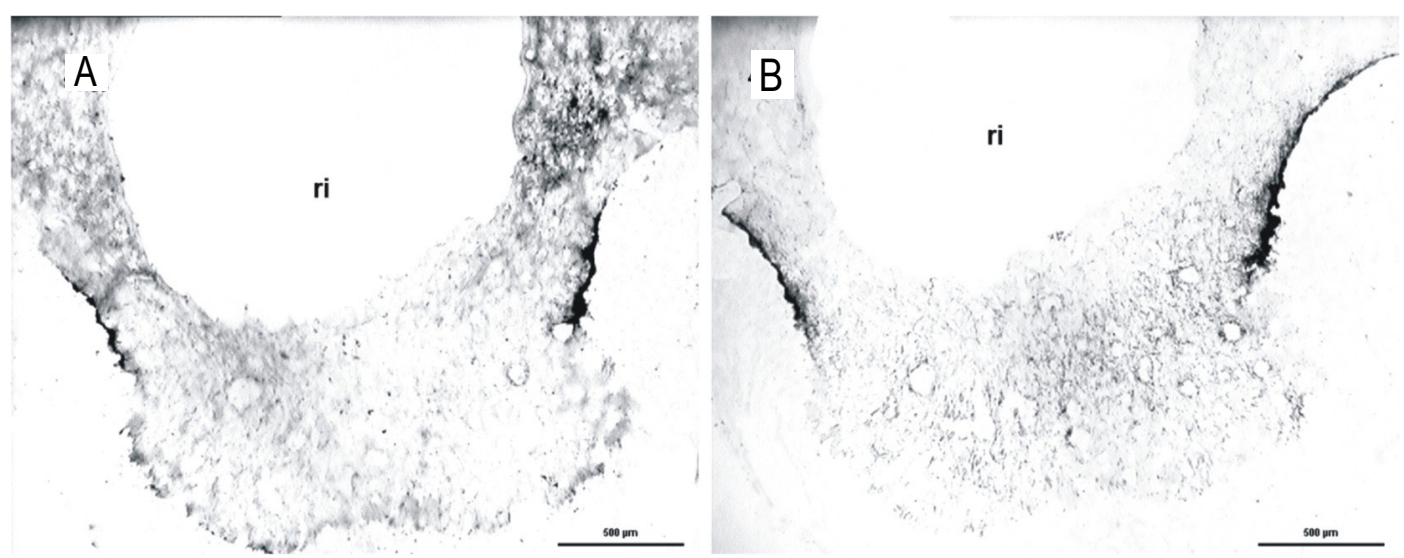

Figure 4. Successive sections showing the distribution of immunoreactive kisspeptin $(A)$ and immunoreactive gonadotrophin releasing hormone $(B)$ nerve terminals in the medial part of the median eminence. Note the superposition of the labelling; $r$ - recessus infundibularis, scale bar $=500 \mu \mathrm{m}$
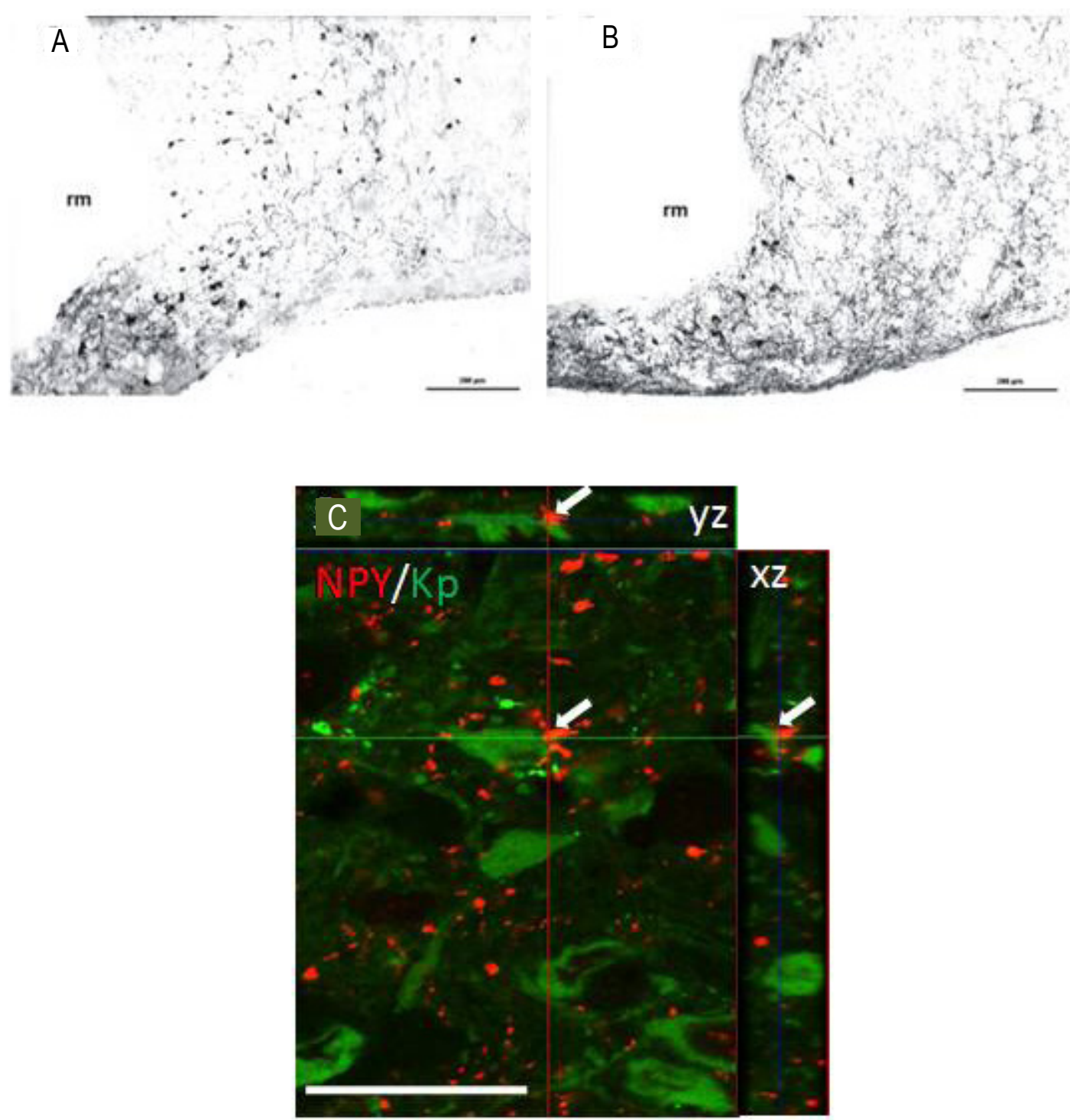

Figure 5. Successive sections showing the distribution of immunoreactive kisspeptin $(A)$ and immunoreactive neuropeptide $Y(B)$ perikarya in the caudal part of the arcuate nucleus. Note the superposition of the labelling; C - Double immunofluorescent staining against NPY (red fibres) and kisspeptin (green cell bodies), observed under confocal microscopy in the arcuate nucleus. The green line and the red line indicate the position of the optical section in the $Y Z$, and $X Z$ plane, respectively. Arrows indicate close apposition of immunoreactive NPY fibres and kisspeptin perikarya; rm- recessus mammilaris, scale bars: $A, B=200 \mu \mathrm{m} ; C=50 \mu \mathrm{m}$ 
The distribution of $\mathrm{kp}$-ir nerve terminals in the ME is presented in Figure 3. Distinct bundles of kpir nerve terminals were seen in the lateral zone of the $\mathrm{ME}$ in its medial division. Nerve terminals were distributed across its medial zone in all parts of the ME from its rostral to caudal division.

\section{Possible connections with GnRH-nerve terminals and NPY-neurons}

In the medial subdivision of the ME, the localization of $\mathrm{kp}$-ir nerve terminals very closely matched the distribution of GnRH-ir nerve terminals (Figure 4). In the caudal part of the ARC nucleus, which is also the main site of NPY synthesis, kp-ir and NPY-ir cell bodies were observed in the same part of the ARC nucleus (Figure 5).

Double immunofluorescence staining for $\mathrm{kp}$ and NPY neurons established the specific immunolabeling for both peptides in the separate perikarya and fibres. Close apposition between the kp-ir cell bodies and NPY-ir fibres was observed under the confocal microscope in the ARC nucleus (Figure 5). For all animals, about $30 \%$ of kp-ir cell bodies showed one or more apposition with NPY-ir fibres.

\section{Discussion}

The present results demonstrate three populations of kp neurons in the hypothalamus of peripubertal sheep. The most apparent centre was located in the ARC nucleus and this is in line with data obtained in adult sheep (Franceschini et al., 2006; Nestor et al., 2012), horses (Decourt et al., 2008), rodents (Clarkson and Herbison, 2006 and monkeys (Ramaswamy et al., 2008). A similar distribution of kpir perikarya and fibres in the hypothalamus has been described in ewes in the luteal phase of their oestrous cycle after colchicine treatment (Franceschini et al., 2006). After such treatment, the axonal transport of secretory products is prevented, their amounts subsequently increase in the cell soma and thus, the perikarya can be seen using immunohistochemistry. In the present work, a high number of kp-ir perikarya was visible in the ARC nucleus during the peripubertal period without using colchicine treatment. These results concern one age group and can not be compared with younger or post-pubertal groups of animals. Our ongoing experiment on growing lambs shows, however, that the number of positive $\mathrm{kp}$ ir cells in this nucleus of the hypothalamus gradually increases from a few visible cells/section in 5-week-old lambs up to almost seventy cells/section in 16-week-old ones (to be published). Recent data obtained on prepubertal (5- to 6-month-old) and post pubertal (9-month-old) female lambs also showed a predominant population of kp perikarya in the ARC nucleus that increased with age (Nestor et al., 2012). The expression of Kiss 1 mRNA is also activated in the ARC nucleus of ewe lambs during juvenile development from 25-35 weeks of age (Redmond et al., 2011). It was demonstrated on ovariectomized ewes treated acutely with E2 that the number of $\mathrm{kp}$ arcuate cells co-labelled with c-fos increased 6-fold, so the authors conclude that these kp neurons are involved in generating the positive feedback preovulatory GnRH/LH surge (Smith et al., 2009b). It was also demonstrated that mainly the subpopulation of arcuate kp neurons is involved in the increased input to GnRH neurons leading to puberty in sheep (Redmond et al., 2011). In conclusion, the visualization and high number of kp arcuate perikarya, without inhibition of axonal transport by colchicine treatment, observed in the present study, may result from their increased secretory activity in the period preceding the first ovulation.

The second population of $\mathrm{kp}$ neurons in our study was only observed to a small extent in the periventricular zone of the AHA and did not create any distinct centre. Similar results have been found in species such as the horse and monkey, in which $\mathrm{kp}$ cell bodies were in general not observed in this area (Decourt et al., 2008; Ramaswamy et al., 2008). These results are different from those observed in rodents (Maeda et al., 2007; Ducret et al., 2010), in which a very large centre of kp perikarya located in the AVPV nucleus was responsible for positive feedback of gonadal steroids.

Kisspeptin perikarya were also located in the MPOA, where they were, however, infrequent and very weakly stained. This site, the centre of GnRH synthesis, suggests that this subpopulation of kp cells can be directly involved in $\mathrm{GnRH}$ activity. It should be underscored here, however, that the data from immunohistochemical studies on sheep describe the presence of these cells in a very general and non-precise way. Kp cells have particularly been observed in mature ewes in the oestrous cycle, in the luteal phase after colchicine treatment (Francheschini et al., 2006), or in the follicular phase (Goodman et al., 2007). In the last of these physiological stages, striking mRNA Kiss 1 expression has been documented in the MPOA-AHA (Smith et al., 2009b). In contrast, in 6-month-old prepubertal female lambs, only single and very lightly stained kp perikarya have been observed in this hypothalamic area (Nestor et al., 2012), similarly to the observations in peripubertal lambs in our study. High expression of kp mRNA has also 
been observed, however (Redmond et al., 2011). These data suggest that during prepubertal development of lambs, the post-translational processing of $\mathrm{kp}$ does not occur in the kp perikarya distributed in the MPOA-AHA. It can, therefore, be supposed that the anterior population of $\mathrm{kp}$ neurons has probably not participated in the prepubertal events in lambs, but most likely plays a role in mechanisms of the oestrous cycle in mature ewes.

In accordance with the important role of both $\mathrm{kp}$ and NPY in the onset of puberty, we studied the possible morpho-functional interactions between NPY ir fibres and kp neurons. We hypothesized that in addition to a direct effect of NPY on GnRH neurons observed in the adult (Norgren et al., 1989; Wójcik-Gładysz et al., 2003), the effect of NPY on GnRH neurons could be indirect and mediated by kp neurons at the onset of puberty. In our study we observed that a third of the kp-ir neurons of the ARC nucleus received at least one or more NPY-ir terminals, this observation supports similar results observed in adult ewes (Backholer et al., 2010). Moreover, using in vitro studies in mice, it has previously been shown that NPY can positively stimulate $\mathrm{kp}$ cells (Lugue et al., 2007).

In addition to their role in gonadotrophic activity in the prepubertal period, NPY neurons are also involved in controlling growth in sheep (Iqbal et al., 2005). In 32-week-old female lambs, we demonstrated that the activity of NPY neurons of the ARC nucleus decreased simultaneously with the number of NPY afferent on PEV somatostatin neurons (Tillet et al., 2010). These results indicate that NPY neurons of the ARC nucleus are able to inhibit growth by suppressing the negative feedback on the somatostatin neurons in the PEV nucleus. Overall, these data lead us to postulate that NPY-containing neurons of the ARC nucleus could play a key role at the onset of puberty through their inhibition of growth via the somatostatin neurons of the PEV nucleus and their stimulation of the gonadotrophic axis the kp-containing neurons of the ARC nucleus. This hypothesis fits with the beginning of puberty that is characterized by a decrease in growth occurring simultaneously with a stimulation of the gonadotrophic axis. The presence of NPY receptors in the $\mathrm{kp}$ neurons remains to be demonstrated.

The present study showed that kp-ir neurons closely overlap the GnRH-ir nerve terminals in the lateral zone of the ME. This neuroanatomical connection between $\mathrm{kp}$ and GnRH would suggest that the essential role of kisspeptin in generating the GnRH/LH surge (Caraty et al., 2007) takes place at the level of GnRH release. Such a hypothesis is supported by in vitro data on isolated ovine ME, whereby incubation of the ME with $\mathrm{kp}$ resulted in significant GnRH release (Smith et al., 2011). Regulation at the level of axon terminals has been suggested in mice, as kp-10 infusion stimulated $\mathrm{GnRH}$ release from nerve terminals in the absence of $\mathrm{GnRH}$ neuronal cell bodies (d'Anglemont de Tassigny et al., 2008). In sheep, a single dose of Kp54 into the third ventricle of the brain resulted in an increase in $\mathrm{GnRH}$ in the cerebrospinal fluid (Messager et al., 2005). The anatomical base for reciprocal control of $\mathrm{kp}$ and GnRH neurons in the ME has been shown by confocal microscopy in the rhesus monkey, in which the co-localization of both kinds of nerve terminals has been demonstrated (Ramaswamy et al., 2008). These morphological interactions have also been observed in the goat and confirmed using electron microscopy (Matsuyama et al., 2011). Using anterograde tracer injections in sheep, projection of $\mathrm{kp}$ neurons to the external zone of the ME was shown to originate primarily from the ARC nucleus (Smith et al., 2011). It can, therefore, be suggested that in this ruminant species, the $\mathrm{kp}$ responsible for the events leading to puberty originates in this hypothalamic centre. Overall, these data point to kp cells of the ARC region acting as mediators in the onset of events leading to the first pubertal surge of $\mathrm{GnRH} /$ LH resulting in the first ovulation.

To conclude, the very high numbers of $\mathrm{kp}$-ir neurons in the ARC nucleus could be attributed to their stimulating action on the GnRH neuronal system during the peripubertal period in the sheep. Furthermore, these neurons could be regulated by NPY, a peptide playing a key role in inducing puberty in mammals.

\section{Acknowledgements}

Supported by the Polish-French Programme Polonium No. 749/2010

\section{References}

Backholer K., Smith J.T., Rao A., Pereira A., lqbal J., Ogawa S., Li Q., Clarke I.J., 2010. Kisspeptin cells in the ewe brain respond to leptin and communicate with neuropeptide $Y$ and proopiomelanocortin cells. Endocrinology 151, 2233-2243

Caraty A., Smith J.T., Lomet D., Ben Said S., Morrissey A., Cognie J., Doughton B., Baril G., Briant C., Clarke I.J., 2007. Kisspeptin synchronized preovulatory surges in cyclical ewes and causes ovulation in seasonally acyclic ewes. Endocrinology $148,5258-5267$

Chaillou E., Baumont R., Chilliard Y., Tillet Y., 1998. Presence of galanin in dopaminergic neurons of the sheep infundibular nucleus: a double staining immunohistochemical study. J. Chem. Neuroanat. 15, 251-259 
Chalivoix S., Bagnolini A., Caraty A., Cognie J., Malpaux B., Dufourny L., 2010. Effects of photoperiod on kisspeptin neural populations of the ewe diencephalon in connection with reproductive function. J. Neuroendocrinol. 22, 110-118

Cheng G., Coolen L.M., Padmanabhan V., Goodman R.I., Lehman M.N., 2010. The kisspeptin neurokinin/dynorphin (KNDy) cell population of the arcuate nucleus: sex differences and effects of prenatal testosterone in sheep. Endocrinology 151, 301-311

Ciofi P., Garret M., Lapirot O., Lafon P., Loyens A., Prevot V., Levine J.E., 2009. Brain-endocrine interactions: a microvascular route in the mediobasal hypothalamus. Endocrinology 150 5509-5519

Clarkson J., Han K., Lin X., Herbison A.E., 2010. Neurobiological mechanisms under laying kisspeptin activation of gonadotropin-releasing hormone $(\mathrm{GnRH})$ neurons at puberty. Mol. Cell. Endocrinol. 324, 45-50

Clarkson J., Herbison A.E., 2006. Postnatal development of kisspeptin neurons in mouse hypothalamus; sexual dimorphism and projections to gonadotropin-releasing hormone neurons. Endocrinology 147, 5817-5825

d'Anglemont de Tassigny X., Fagg I.A., Carlton M.B., Colledge W.H., 2008. Kisspeptin can stimulate gonadotropin-releasing hormone $(\mathrm{GnRH})$ release by a direct action at $\mathrm{GnRH}$ nerve terminals. Endocrinology 149, 3926-3932

Decourt C., Tillet Y., Caraty A., Francheschini I., Briant C., 2008, Kisspeptin immunoreactive neurons in the equine hypothalamus interactions with $\mathrm{GnRH}$ neuronal system. J. Chem. Neuroanat.137, 131-137

De la Iglesia H.O., Schwartz W., 2006. Minireview: timely ovulation, circadian regulation of the female hypothalamo-pituitary-gonadal axis. Endocrinology 147, 1148-1153

De Roux N., Genin E., Carel J.C., Matsuda F., Chaussain J.L., Milgrom E., 2003. Hypogonadotrophic hypogonadism due to loss of function of the KiSS1- derived peptide receptor GPR54.. Proc. Nat. Acad. Sci. USA 100, 10972-10976

Ducret E., Gaidamaka G., Herbison A.E., 2010. Electrical and morphological characteristics of anteroventral periventricular nucleus kisspeptin and other neurons in the female mouse. Endocrinology 151, 2223-2232

Estrada K.M., Clay C.M., Pompolo S., Smith J.T., Clarke I.J., 2006. Elevated KISS-I expression in the arcuate nucleus prior to the cyclic preovulatory gonadotrophin-releasing hormone/luteinising hormone surge in the ewe suggest a stimulatory role for kisspeptin in oestrogen-positive feedback. J. Neuroendocrinol. 18, 806-809

Francheschini I., Lomet D., Cateau M., Delsol G., Tillet Y., Caraty A., 2006. Kisspeptin immunoreactive cells of the ovine preoptic area and arcuate nucleus co-express estrogen receptor alpha. Neurosci. Lett. 401, 225-230

Goodman R.L., Lehman M.N., Smith J.T., Coolen L.M., De Oliveira C.V.R., Jafarzadehshirazi M.R., Pereira A., Iqbal J., Caraty A., Ciofi P., Clarke I.J., 2007. Kisspeptin neurons in the arcuate nucleus of the ewe express both dynorphin $A$ and neurokinin B. Endocrinology 148, 5752-5760

Iqbal J., Manley T. R., Ciofi P., Clarke I.J., 2005. Reduction in adiposity affects the extent of afferent projections to Growth Hormone-Releasing Hormone and somatostatin neurons and the degree of colocalization of neuropeptides in Growth Hormone-Releasing Hormone and somatostatin cells of the ovine hypothalamus. Endocrinology 146, 4776-4785

Kalra S.P., Crowley W., 1992. Neuropeptide Y: a novel neuroendocrine peptide in the control of pituitary hormone secretion and its relation to luteinizing hormone. Front. Neuroendocrinol. 13, 1-46
Kotani M., Detheux M., Vandenbogaerde A. et al., 2001. The metastasis suppressor gene KISS-1 encodes kisspeptins, the natural ligands of the orphan $\mathrm{G}$ protein-coupled receptor GPR54. J. Biol. Chem. 276, 34631-34636

Liposits Z., Sétaló G., Flérko G., 1984. Application of the silver-gold intensified 3, 3'-diaminobenzidine chromogen to the light and electron microscopy detection of the luteinizing hormonereleasing hormone system in the rat brain. Neuroscience 13 , 513-525

Lugue R.M., Kineman R.D., Tena-Sempere M., 2007. Regulation of hypothalamic expression of KISS-1 and GPR54 genes by metabolic factors: analyses using mouse models and a cell line. Endocrinology 148, 4601-4611

Maeda K., Adachi S., Inoue K., Ohkura S., Tsukamura H., 2007. Metastin/kisspeptin and control of estrous cycle in rats. Rev. Endocr. Metab. Dis. 8, 21-29

Matsuyama S., Ohkura S., Mogi K., Wakabayashi Y., Mori Y., Tsukamura H., Maeda K., Ichikawa M., Okamura H., 2011. Morphological evidence for direct interaction between kisspeptin and gonadotropin-releasing hormone neurons at the median eminence of the male goat: an immunoelectron microscopic study. Neuroendocrinology 94, 323-332

Messager S., Chatzidaki E.E., Ma D. et al., 2005. Kisspeptin directly stimulates gonadotropin-releasing hormone release $\mathrm{G}$ protein-coupled receptor 54. Proc. Nat. Acad. Sci. USA 102, 1761-1766

Nestor C.C., Briscoe A.M.S., Davis S.M., Valent M., Goodman R.L., Kileman S.M., 2012. Evidence of a role for kisspeptin and neurokinin $B$ in puberty of female sheep. Neuroendocrinology 153, 2756-2765

Norgren Jr. R.B., Lehman M.N., 1989. A double-label pre-embedding immunoperoxidase technique for electron microscopy using diaminobenzidine and tetramethylbenzidine as markers. J. Histochem.Cytochem. 37, 1283-1289

Oakley A.E., Clifton D.K., Steiner R.A., 2009. Kisspeptin signaling in the brain. Endocrine Rev. 30, 731-743

Ohkamura S., Takase K., Matsuyama S., Mogi K., Ichimaru T., Wakabayashi Y., Uenoyama Y., Mori Y., Steiner R.A., Tsukamura H., Maeda K. I., Okamura H., 2009. Gonadotrophin-releasing hormone pulse generator activity in the hypothalamus of the goat. J. Neuroendocrinol. 21, 813-821

Polkowska J.,Wańkowska M., Wójcik-Gładysz A., 2006. Expression of NPY-immunoreactive neurons in the hypothalamus of the cycling ewe. Folia Histochem. Cytobiol. 44, 13-16

Porter D.W.F., Naylor A.M., McNeilly A.S., Lincoln D.W., 1993. Endocrine actions of central neuropeptide $Y$ in the ewe: activation of the hypothalamo-pituitary-adrenal axis by exogenous neuropeptide $Y$ and role of endogenous neuropeptide $Y$ in the secretion of luteinizing hormone during the oestrous cycle. J. Neuroendocrinol. 5, 163-174

Przekop F., Ciechanowska M., 2012. Kisspeptin (kiss 1) network signalling of hypothalamic gonadotropin-releasing hormone (GnRH) neurons. J. Anim. Feed Sci. 21, 397-424

Ramaswamy S., Guerriero K.A., Gibbs R.B., Plant T.M., 2008. Structural interactions between kisspeptin and $\mathrm{GnRH}$ neurons in the medial-basal hypothalamus of the male rhesus monkey (Macaca mulatta) as revealed by double immunofluorescence and confocal microscopy. Endocrinology 149, 4387-4395

Redmond J.S., Baez-Sandoval G.M., Snell K.M., Spencer T.F., Lents C.A., Williams G.L., Amstalden M., 2011. Developmental changes in hypothalamic Kiss1 expression during activation of the pulsatile release of luteinizing hormone in mature ewe lambs J. Neuroendocrinol. 23, 815-822 
Seminara S.B., Messager S., Chatzidaki E.E. et al., 2003. The GPR54 gene as a regulator of puberty. N. Engl. J. Med. 349, 1614-1627

Smith J.T., Clay C.M., Caraty A., Clarke I.J., 2006a. Kiss-1 mRNA expression in the hypothalamus of the ewe is regulated by sex steroids and season. Endocrinology 148, 1150-1157

Smith J.T., Li Q., Pereira A., Clarke I.J., 2009b. Kisspeptin neurons in the ovine arcuate nucleus and preoptic area involved in the preovulatory surge. Endocrinology 150, 5530-5538

Smith J.T., Li Q., Yap K.S., Shahab M., Roseweir A.K., Millar R., Clarke I.J., 2011. Kisspeptin is essential for the full preovulatory LH surge and stimulates $\mathrm{GnRH}$ release from the isolated ovine median eminence. Endocrinology 152, 1001-1012

Smith J.T., Popa S.M., Cklifton D.K., Hoffman G.E., Steiner R.A., 2006b. Kiss1 neurons in the forebrain as central processor for generating the preovulatory luteinizing hormone surge. J. Neurosci. 26, 6687-6694

Smith J.T., Salch S.N.H., Clarke I.J., 2009a. Seasonal and cyclical change in the luteinizing hormone response to kisspeptin in the ewe. Neuroendocrinology 90, 283-291
Stupnicki R., Kula E., 1982. Direct radioimmunoassay of progesterone in human plasma. Endokrinologie 80, 1-7

Tillet Y., Caldani M., Batailler M., 1989. Anatomical relationships of monoaminergic and neuropeptide $Y$-containing fibers with luteinizing hormone-releasing hormone systems in the preoptic area of the sheep brain. immunohistochemical studies. J. Chem. Neuroanat. 2, 319-326

Tillet Y., Picard S., Bruneau G., Ciofi P., Wańkowska M., WójcikGładysz A., Polkowska J., 2010. Hypothalamic arcuate neuropeptide Y-neurons decrease periventricular somatostatin-neuronal activity before puberty in the female lamb: morphological arguments. J. Chem. Neuroanat. 40, 265-271

Welento J., Steyn S., Millart Z., 1969. Observations o the stereotaxic configuration of the hypothalamus nuclei in the sheep. Anat. Anz. 124, 1-27

Wójcik-Gładysz A., Misztal T., Wańkowska M., Romanowicz K., Polkowska J., 2003. Effect of central infusions of neuropeptide $\mathrm{Y}$ on $\mathrm{GnRH} / \mathrm{LH}$ axis in ewes during the early anoestrous period. Reprod. Biol. 3, 29-46 